\title{
A Estética da Diferença e o Ensino das Literaturas de Língua Inglesa
}

Cielo Griselda Festino ${ }^{a}$

\begin{abstract}
Resumo
O objetivo deste artigo é discutir o conceito de estética e a sua relevância para o ensino das literaturas de lingua inglesa no momento quando a disciplina Literatura Inglesa tem sido reformulada como Literaturas de Língua Inglesa para incluir as narrativas literárias não somente de tradições literárias canônicas como a inglesa ou a norte-americana, mas também das culturas que foram colonias inglesas e hoje têm suas próprias tradições literárias nacionais em língua inglesa. Nesse contexto, o conceito de estética será considerado em contraponto com o conceito de diferença, tanto a nível literário quanto a nível cultural.
\end{abstract}

Palavras-chave: estética, diferença, cânone literário

\footnotetext{
a Professora titular da Universidade Paulista. cielofestino@gmail.com
} 


\section{Introdução}

David Damrosch (2009, p. 13) assinala que sempre se deve considerar o contexto de produção de uma narrativa literária, especialmente daquelas de culturas distantes de nós em tempo e espaço, porque nos ajuda a reconhecer a pluralidade da estética e suas diferentes manifestações. Essa perspectiva, diz o autor, faz "nos deter em momentos da narrativa que parecem ilógicos ou exagerados, ou monótonos" (2009, p. 13) porque são, justamente, esses momentos os que se apresentam como janelas a outras culturas diferentes da nossa. A partir dessa perspectiva é que achamos relevante fazer uma leitura crítica do conceito do literário, como um conceito definido localmente e, no panorama atual, em contraponto com outras visões de literatura em outras partes do mundo.

Entendemos que essas reflexões são de grande relevância na aula da disciplina "Literaturas de Língua Inglesa" hoje, quando o seu curriculum tem se expandido para abraçar as chamadas "novas literaturas" ou "literaturas pós-coloniais", noutras palavras, as literaturas das ex-colônias inglesas.

\section{Os Conceitos de "Estética" e de "Diferença"}

Para poder se aproximar do Outro por meio das narrativas literárias, é preciso rever os conceitos de estética e de diferença; eles aparecem como opostos entre si. O primeiro evoca o que é universal, único, comum, homogêneo, natural, desinteressado, idealista, metafísico (FREITAS CATON, 2002, p. 279), enquanto o segundo aponta para o que é local, situado, contingente, múltiplo, heterogêneo, considerado de uma determinada perspectiva comunitária. Vistos de maneira isolada e fora de qualquer contextualização histórica e cultural, os termos se apresentam como irreconciliáveis. Porém, no panorama mundial, após a Segunda Guerra Mundial, quando as utopias anticoloniais têm se tornado pesadelos pós-coloniais e globais (HALL, 2005, p.1), a estética, entendida como universal, torna-se suspeita de colaborar para uma ideologia hegemônica e precisa ser reconsiderada e qualificada em termos da nova relação entre culturas que têm se afirmado nas últimas décadas com o fluxo constante das margens para o centro, ou seja, das ex-colônias para as grandes metrópoles europeias e norte-americanas. 
A ideia da estética como uma concepção única está associada com os valores ocidentais, como sendo uma perspectiva verdadeira e genuína. Isso já vem mostrar que a estética não é desinteressada, mas privilegia uma determinada ideologia que tenta passar por universal. Eagleton (1990, p. 25) assinala o equívoco dessa visão da estética ao apontar que, assim entendida, ela internaliza a repressão, a colonização e a subjugação das massas, e o desejo que as diferentes culturas onde se instala rejeitem os interesses de sua comunidade, em favor de um bem-comum desinteressado.

A visão universalista da estética é o resultado, como assinala Freitas Caton (2002, p. 280), da ideia de que o estético é o produto de uma relação sensorial individual com o mundo que nos rodeia, independente de lugar e tempo. O que deve ser levado em conta é que se a experiência sensorial é comum a todo ser humano, ela sempre será mediada pelo contexto cultural a que o indivíduo pertence; ou seja, é uma prática comunitária que depende do que é entendido como estético dentro da comunidadeà qual o indivíduo pertence.

Ickstadt $(2002$, p. 265) aponta que, uma vez que as certezas sobre valor, objetividade, universalidade e hierarquia do Iluminismo têm sido problematizadas pelas epistemologias pós-estruturalistas, as questões de estética podem ser consideradas como sendo instáveis e em constante transformação. Por isso, a partir das teorias pós-coloniais (SAID, 1978; BHABHA, 1994), entendemos o discurso da estética como sendo plural, socialmente localizado, comum aos membros de uma determinada comunidade e não uma prática de privilégio reservada a uns poucos iniciados.

Quando a estética é entendida como uma prática comunitária e diretamente relacionada com a cultura em que é experimentada, percebemos que culturas diversas têm diferentes teorias estéticas, propõem metáforas literárias que têm marcas das culturas em que são desenvolvidas e, por extensão, vão se relacionar com o que é considerado como uma obra de arte de maneira diferenciada. Essa visão pluralista dá origem a uma estética da diferença que, em um nível, torna visível o aspecto não somente estético, mas também social da literatura e, em outro nível, contribui para a convivência com esse Outro diferente.

$\mathrm{O}$ termo diferença merece ser considerado em detalhe. John D. Caputo (1993, p. 44) chama atenção para o conceito de 
diferença pelas suas leituras de Deleuze, Derrida e Nietzsche apontando que o jogo (play) entre o que ele chama de energias (e nós traduzimos como discursos) nunca se solidifica através da dialética em uma relação oposicional. Pelo contrário, por meio de uma relação dialógica, que sempre está acontecendo e se transformando, a relação entre essas forças sempre é diferencial e relacional.

Assim, em vez de considerar a diferença como uma alteridade hierarquizada e fixa, um outro singular e não plural, não um entre muitos, mas um só, que submete e coloniza o Outro, Caputo (1993, p. 60) aponta que a diferença pode ser entendida como um jogo (play) permanente entre forças eruptivas e não disruptivas por meio das quais se geram as diferentes identidades culturais.

Essa relação dialógica entre forças (ou discursos) pode ser entendida a partir do que Derrida (1988) chama de centro e que funciona como elemento organizador, mas que não é fixo, senão temporário e funcional. A participação de novas forças (ou discursos) faz com que esse centro seja deslocado até que um novo centro se estabeleça, em um sem fim de continuidade. Seria essa a relação entre os diferentes discursos de um cânone literário: uma acomodação da tradição com a chegada de novas narrativas. Porém, esse movimento não se deve somente à qualidade da metáfora literária, como já apontou T. S. Eliot (1951) no seu famoso ensaio, Tradition and the Individual Talent, mas também a fatores ideológicos.

A partir do conceito derrideano de disseminação, como observa Caputo (1993, p. 55), a diferença é sempre experimental e inovadora, multiplica-se em múltiplos contextos e implica $o$ amor das formas diferentes. É isso o que a estética da diferença tem como objetivo: o amor do Outro por meio da apreciação de formas diferentes. Assim considerado, o Outro não é um inimigo, mas aquele cuja cultura marca os limites da nossa e ajuda-nos a refletir sobre a própria cultura ao mesmo tempo que contribui para nos liberar dos tabus da nossa sociedade.

\section{O Literário: um conceito plural}

É a partir dessa estética da diferença que entendemos o conceito do literário não como uma categoria universal, mas como culturalmente contingente: uma das formas estéticas que, 
em conjunto com a imaginação, articula o que um povo aprende da sua experiência: sabedoria, preconceitos, costumes, crenças, práticas etc. Literatura tem significado diferentes coisas para diferentes culturas através dos séculos. Assim, por exemplo, a leitura dos poetas românticos ingleses não necessariamente nos ajuda a apreciar outras manifestações poéticas como um ghazal indiano em língua urdu. Isso se deve a que cada cultura não só tem suas próprias estratégias retóricas e estilos, mas também uma maneira diferenciada de entender, por exemplo, conceitos como o amor, o que está longe de ser uma categoria universal.

Diferentes culturas entendem a literatura e seu papel na sociedade de maneiras diferenciadas; por sua vez, ainda dentro de uma cultura, os significados atribuídos ao termo não são estáveis. Damrosch (2009, p. 13-14) aponta que, na tradição ocidental que remonta a Platão e Aristóteles, a literatura tem sido associada com a imaginação, o que se reflete na palavra "poesia" que, em grego, significa "fazer", e na palavra "ficção" do Latim "facere" que também significa "fazer".

Logo, como assinala Damrosch (2009, p. 6), ainda no mundo ocidental, o termo literatura foi utilizado para se referir às narrativas "escritas com belas palavras" e sugere que essa beleza da linguagem é mais relevante do que qualquer uso ou afirmação do texto. A frase belles lettres era utilizada para se referir a qualquer tipo de composição de marcado valor retórico como poesias, estórias, diálogos filosóficos ou discursos políticos.

Se no século dezoito o termo literatura era mais amplo, acrescenta Damrosch (2009, p.7), na primeira metade do século dezenove, o Ocidente restringiu o conceito de literatura àquelas narrativas, ainda parte das "Belles Lettres", mas produto da imaginação. Foi essa ênfase no aspecto criativo da literatura que fez com o que o literário fosse considerado uma classe de discurso puramente estético, desengajado politicamente como a famosa frase da "arte pela arte mesma" atesta. Ickstadt (2002, p. 269) aponta que uma vez que um texto é marcado como estético, ele pode ser lido pelo seu conteúdo político. Contudo, o dominante principal seguirá sendo estético. Em outras culturas, porém, os textos literários podem ter valor histórico ou moral, além de qualquer consideração estética.

Damrosch (2009, p. 7) explica, então, que em outras culturas, como por exemplo a chinesa, o termo wen é traduzido como literatura quando se refere à poesia e prosa artística, mas 
implica determinados significados e conceito de harmonia que se refletem nos desenhos, padrões e ordem conferidos à palavra escrita. O que também se espera é que as ideias articuladas por meio da literatura estejam intimamente relacionadas com o que a cultura entende como realidade.

Da mesma maneira, na cultura indiana, fato e ficção estão intimamente ligados. Para Gandhi, os textos por meio dos quais se podia ter acesso à história da cultura eram os grandes épicos indianos como o Ramayana, o Mahabharata e o Bhagavad Gita (FESTINO, 2007). Eram esses textos que articulavam os valores da comunidade. Enquanto para um leitor ocidental as histórias narradas neles sempre serão exemplos de narrativas épicas, produtos da imaginação, para os indianos elas têm a mesma importância que uma narrativa histórica. É muito citado o prefácio do romance Kanthapura (1938) no qual o autor indiano Raja Rão explica a relação entre literatura e história na cultura indiana:

There is no village in India, however mean, that has not a rich sthala-purana, or legendary history, of its own. Some god or godlike hero has passed by the village -Rama might have rested under this pipal-tree, Sita might have dried her clothes, after her bath, on this yellow stone, or the Mahatma himself, on one of his many pilgrimages through the country, might have slept in this hut, the low one, by the village gate. In this way, the past mingles with the present, and the gods mingle with men to make the repertory of your grandmother always bright. One such story from the contemporary annals of a village I have tried to tell.

Como se pode perceber na passagem, na narrativa homens e deuses habitam o mesmo espaço, ao mesmo tempo em que passado e presente estão lado a lado. Em contraponto, como aponta Damrosch (2009, p. 7), embora um romance da Revolução Francesa seja tão cativante como um romance não histórico, os leitores esperam que todos os eventos da narrativa estejam claramente relacionados a documentos que o historiador tenha lido, mas não tenha inventado.

De outro ângulo, os diferentes gêneros literários variam de uma cultura para outra, tanto na sua forma como na sua recorrência. Um ghazal indiano vai diferir de um soneto shakesperiano. Da mesma maneira, dentro de uma cultura, os diferentes gêneros literários são considerados de maneira 
diferente. A modo de exemplo, o gênero poesia era bem mais central do que as narrativas em forma de prosa na cultura indiana pré-colonial. Por sua vez, enquanto o gênero romance é um produto da cultura ocidental, no século dezenove há diferenças marcantes entre o romance inglês, de caráter sociológico, e o romance russo, que se distingue pela sua qualidade psicológica. Ainda dentro da Índia há um tipo de literatura, como o relato autobiográfico, que pertence aos membros da casta dos Dalit, ou intocáveis. Essas narrativas muitas vezes não são reconhecidas como literatura pelos membros das chamadas castas superiores porque, na sua opinião, elas não têm valor literário (LIMBALE, 2004, p.8).

Então, literatura seria o conjunto de todas aquelas narrativas consideradas "literárias" na sua cultura de origem porque os usuários desse tipo de textos as reconhecem como tal. Como temos visto, narrativas que são consideradas como literárias em um contexto podem não ser consideradas da mesma maneira em outros contextos. Isso quer dizer, por um lado, que o conceito de literatura não é universal e, pelo outro, que o literário não é uma essência, mas é produto da interação que se estabelece entre o leitor e o texto, mediada pelo contexto cultural.

Um outro exemplo seriam os objetos de culturas indígenas que, na sua cultura de origem, têm um valor prático, ou religioso e, em culturas ocidentais, são tratados como objetos de arte. Ainda dentro das fronteiras nacionais, seriam objetos ordinários que se tornam objetos de arte, quando incorporados a um museu ou uma mostra de arte como uma instalação. $\mathrm{Ou}$ seja, o que muda o valor do objeto não é alguma qualidade intrínseca, mas o contexto cultural que faz com que os objetos sejam impregnados de um valor social ou de um valor estético (ICKSTADT, 2002, p. 268). Mais um exemplo seria que textos considerados como sagrados por uns, o caso da Bíblia, são tratados como literatura por outros.

Essas diferentes epistemologias estéticas estão em uma relação hierárquica de poder fora e dentro dos limites da nação. Dentro, na relação que se estabelece com o que se considera como literatura canônica ou literatura regional. Fora, entre as diferentes tradições nacionais em línguas diferentes, ou na mesma língua, como no caso das línguas multiculturais como o inglês, por exemplo. 
Quando alguém, por um julgamento estético, declara como bela a produção cultural ou artística de uma outra pessoa ou cultura, a estética funciona como uma ponte que vai além da diferença. Pelo contrário, quando alguém de um grupo social conservador, considerado de elite ou de uma cultura reconhecida como hegemônica desacredita a estética de outra pessoa ou cultura como sendo inferior, a estética torna-se uma ferramenta de opressão (ELLIOT, 2002, p. 3).

Isso vem mostrar que a estética não é inocente, mas que, ao declarar que uma obra artística é complexa ou banal, pertence a um artista maior ou menor, questões ideológicas perpassam o seu discurso. Quem faz esse tipo de asseveração considera a sua estética como universal, fora de qualquer questão de lugar e tempo e ignora diferenças culturais e históricas. Por sua vez, tenta impor os valores de seu grupo de elite como universais e estáveis e julga qualquer tipo de expressão cultural e artística a partir desse paradigma.

Ainda dentro das fronteiras nacionais, embora haja um cânone literário estabelecido, reconhecido como "literatura nacional", as narrativas que o conformam não são um conjunto homogêneo, porque as diferentes comunidades que formam a nação, as que se distinguem por região, classe, faixa etária, gênero, etc., têm suas próprias narrativas, muitas vezes diferentes entre si no estilo e no conteúdo. $\mathrm{O}$ que acontece é que nem todas essas narrativas são reconhecidas como literatura pelos guardiões do cânone nacional.

No caso das línguas multiculturais, como a inglesa, muitas vezes acontece que epistemologias estéticas, de grupos considerados como mainstream ou como minorias, hegemônicos ou periféricos, distantes umas das outras, (no sentido de representar o que é conhecido como o Oriente e Ocidente), são articuladas em uma língua comum, neste caso a inglesa, o que leva a agrupá-las dentro da mesma tradição e epistemologia estética. Porém, todas essas epistemologias e culturas que as articulam estão marcadas pela diferença e estão em contraponto umas com as outras, por uma relação hierárquica de poder.

Por sua vez, o fato de estarem articuladas na mesma língua reforça o estranhamento que se produz quando nos confrontamos com narrativas literárias provenientes de culturas que, a princípio, nem sempre associamos com essa língua 
e que se revelam totalmente diferentes do esperado. O desconhecimento dessas epistemologias leva, em alguns casos, a apagar seu diferencial quando passadas pelo cerne das nossas epistemologias e, em outros casos, a desqualificar as metáforas dessas narrativas como sendo inferiores, pelo fato de não se assemelharem às na nossa tradição.

É famosa a anedota do historiador inglês Babington Macaulay (1834, p. 241) para quem "uma estante de livros de literatura inglesa" era superior a toda a literatura produzida no Oriente. Esse processo leva, ao mesmo tempo e paradoxalmente, a reduzir as narrativas literárias do Outro diferente a narrativas biográficas, sociais ou antropológicas, como se elas não tivessem valor estético ou literário, simplesmente porque não o sabemos reconhecer. Esse exemplo revela que a estética pode colonizar a nossa imaginação e, muitas vezes, imposibilitar-nos de enxergar outras maneiras artísticas de narrar e compreender o mundo. Porém, e essa é a nossa proposta, a estética pode também desafiar essas maneiras canônicas de ler o mundo.

Ao mesmo tempo, as epistemologias estéticas nem sempre são assim transparentes. Ainda na própria cultura e língua, pode acontecer que textos escritos em outros períodos literários, em outros grupos sociais e em outros estilos literários resultam de difícil leitura para um leitor contemporâneo. Tudo isso mostra que as epistemologias estéticas, como qualquer outro sistema cognitivo, estão em um constante processo de tensão e transformação.

O reconhecimento dessa condição nos leva a desenvolver uma perspectiva crítica, a desfamiliarizar as próprias práticas literárias com o intuito de mostrar, como também aponta Fish (1982), que elas são o resultado das práticas de leitura de nossa própria cultura, entendida também como comunidade interpretativa e, por extensão, não naturais, mas construídas.

Esse processo de reconhecimento da estética da diferença se realiza não somente pela inclusão de textos de outras culturas, consideradas não hegemônicas ou de minoria no currículo escolar, mas por meio de uma reconsideração da estética como plural e culturalmente situada. Como temos visto, diferentes culturas desenvolvem diferentes concepções de arte e narrativa. 
Então, como aponta Damrosch, se lemos um texto estrangeiro sem levar em conta os valores da cultura onde foi produzido,

...corremos o risco de reduzi-lo a uma pálida versão de formas literárias conhecidas para nós, como se Homero tivesse tentado escrever romances, mas não soube como desenvolver a personagem ou um haikai japonês fosse um soneto que ficou sem força depois de dezessete sílabas (DAMROSCH, 2009, p. 1; tradução nossa).

Essa pluralização da noção de estética traz conjuntamente uma profusão de significados na leitura dos textos literários que vai depender do contexto em que a leitura é realizada. Quando o texto literário é considerado como autossuficiente e a estética como universal, os muitos significados do texto, como aponta Freitas Caton (2002, p. 283), sempre são controlados pelo conceito de unidade e organicidade do texto (inerente a ele) e um sentido único da estética. Por outro lado, o caso de uma literatura multicultural, como a inglesa, no momento da presente globalização, revela que nenhuma epistemologia estética é pura, já que há influência mútua mostrando, em outro nível, que toda cultura é profundamente híbrida.

Lauter (2002, p. 210) aponta que, como Walt Whitman, devemos abraçar a contradição segurando, com uma mão, o hibridismo e a interpenetração e, com a outra, celebrando o local, o particular e a diferença. A tarefa da estética, como a da política, é segurar essas aparentes contradições em um abraço tenso, mas? criativo.

\section{A Ética da Estética}

A estética sempre tem tido uma dimensão ética que tem servido a diferentes ideologias e interesses, de dominação ou de libertação. A estética entendida como uma visão universalizante pode se tornar uma prática de exclusão e dominação. Como é sabido, as narrativas literárias são uma das formas mais efetivas de persuasão cultural, como a sua contribuição para a formação de uma identidade nacional e seu uso como ferramenta de dominação colonial revelam.

A modo de exemplo, a historiografia da disciplina "Literatura Inglesa" mostra que ela foi primeiramente aplicada na Índia como ferramenta de colonização, porque, por meio de 
suas narrativas, repassavam-se para os indianos, tidos como uma cultura primitiva, os valores da cultura inglesa (VISWANATHAN, 1989). Logo, foi o canal pelo qual se repassaram para os trabalhadores do norte da Inglaterra e para as mulheres os valores da classe social dominante inglesa. Somente na segunda metade do século dezenove, será ministrada a disciplina "English Studies" em Oxford e Cambridge, junto aos estudos clássicos (PALMER, 1965, p. vii).

Para Matthew Arnold (1869), as narrativas que compunham o cânone inglês tinham um status quase sagrado no sentido de que articulavam os valores mais sofisticados da cultura inglesa. Como explica Chamberlin (2003, p. 23), Arnold estava falando no meio de uma Inglaterra dividida por motivos sociais (ricos e pobres), econômicos (o Norte Industrial e o Sul agrário) e políticos (a dramática extensão do voto). Então, a imposição de nossas narrativas sobre as deles era uma maneira de evitar o que ele entendia como anarquia e barbárie. Esse desejo de unificação fez com que a literatura se tornasse uma ferramenta de opressão social e cultural ao impor os valores das elites dominantes a colonizados, classe baixa e mulheres.

Chamberlin (2003, p. 25) acrescenta que a imposição dos valores segundo Arnold era uma escolha entre duas alternativas falsas (cultura e barbárie) que continua vigente ainda hoje. Esse tipo de ideologia se manifesta no fato de prestigiar os valores de um panteão de escritores, homens, brancos e euro-americanos, nunca sujeito a mudanças, o qual revela que, muitas vezes, o que se considera como universal é o cânone Ocidental. Quem não se encaixar dentro dele é considerado como inferior ou marginalizado (ELLIOTT 2002, p.3-9). Por esses motivos, a estética pode ser explorada para reafirmar preconceitos nacionais, raciais, de gênero etc. Um exemplo desses fatos é o famoso livro O cânone ocidental (1994), de Harold Bloom.

Nas últimas décadas e, a partir de uma estética da diferença, que dá relevância ao aspecto social, a estética tem-se tornado uma prática de inclusão que considera o elemento de conflito na convivência entre grupos de interesses diferentes. Essa visão social da estética leva a uma leitura que considera a maneira como a metáfora literária articula as experiências do dia a dia dos leitores mediadas por questões de classe, raça, gênero, etnia, etc., em vez de tentar escapar dos conflitos sociais pela imposição de valores morais e éticos e a transcendência a 
algum plano superior, abstrato e universal, possibilitado pelo caráter sublime da metáfora literária.

É essa relação da obra de arte com o seu contexto de produção que faz com que a experiência estética não isole as narrativas literárias. Dewey explica que, para entender a arte na sua forma final, como é apresentada para o público, é preciso começar

...com as cenas e eventos que chamam a atenção do olhar e do ouvido do homem e que lhe causam prazer ao escutar ou enxergá-las: a visão de uma multidão, um homem suspenso no ar em um palanque, a graça do jogador de bola que cativa a audiência, uma dona de casa tomando conta de uma plantinha...(1934, p. 3; tradução nossa)

Enfim, as experiências que fazem o cotidiano do homem e da mulher comum. Entendemos que o que Dewey faz, por esse comentário, é tirar a arte de seu pedestal, afastada do mundo pelo seu halo de sofisticação e complexidade, para reconectá-la com as nossas experiências diárias. A estética, da perspectiva de Dewey, não é uma experiência para um grupo de privilégio, mas é o que nos permite desfrutar de nossas atividades diárias. É por isso que, na opinião do filósofo, a arte que tem mais vitalidade é a arte que se considera como popular: o cinema, os gibis, os gêneros policiais etc., enquanto a arte que é relegada ao museu perde a sua energia, tende a se tornar anêmica, e fica isolada e relegada a uns poucos (DEWEY, 1934, p. 34).

Quando, por outro lado, continua Dewey, resgatamos de seu nicho sagrado as obras de arte que nossa admiração cobre com uma aura quase espiritual, reforçamos o vínculo que essas obras têm com seu contexto social, uma vez que elas embelezam nosso cotidiano.

Em outro nível, essa leitura social da arte contribui para uma sensibilização com a cultura do Outro, tanto dentro como fora das fronteiras nacionais, pela desconstrução de estereótipos culturais. Essa função da estética tem a ver com seu aspecto ético.

Poder enxergar além dos limites do próprio discurso estético e visualizar o discurso estético dos outros torna-se uma prática que é, como assinala Freitas Caton (2002, p. 281), solidária e emancipatória, porque nos ajuda a enxergar o 
mundo da perspectiva do Outro, e nos libera dos próprios preconceitos; assim, a estética passa de uma prática que se mostra como desinteressada, restrita ao estético, a uma prática socialmente engajada que se torna ferramenta de mudança social.

Considerado dessa maneira, o conteúdo estético e afetivo das narrativas literárias torna-se um canal adequado para uma renovação da sociedade em geral e, no caso das literaturas estrangeiras, torna-se um discurso mediador das relações entre diferentes culturas. Brydon (2007, p. 4) cita a poeta norte-americana Adrienne Rich, para quem “...o estético não é uma visão privilegiada e isolada do sofrimento humano, mas uma notícia de conscientização, de resistência que os sistemas totalizantes querem subjugar: a arte alcança o que ainda é apaixonado, ainda não é reprimido, ainda não é subjugado".

Quando interpretadas, como sugere Rich, como uma prática de conscientização, as narrativas literárias, pelo plano estético, entram no plano cultural e levam à reflexão sobre o lócus de enunciação do Outro e do Eu.

Dessa maneira, pela leitura de textos literários, entendidos como construções históricas e sociais que, por sua vez, não só afirmam, mas também interrogam a história das diferentes culturas, passa-se a perceber o modo em que a própria cultura se relaciona com outros locais e, por meio desse posicionamento crítico, torna-se parte de um processo de mudança. Assim, como sugere Giroux (2006, p. 22), falando da educação em sentido lato, a aula de literatura em geral e a estrangeira em particular tornam-se um terreno em que o aprendizado está intimamente ligado a conceitos de lugar, identidade, história e poder, uma vez que permitem uma reconsideração não só da leitura de textos produzidos em culturas tidas como hegemônicas ou periféricas, mas também dos círculos de poder (acadêmicos, políticos, editoriais etc.) que legitimam a leitura de determinados textos em detrimento de outros.

Vista dessa maneira, a estética não é cúmplice, mas ajuda a desmascarar qualquer ideologia. Como aponta Derrida (1992, p. 58; tradução nossa): "A Literatura em geral é um lugar institucional e selvagem; um lugar institucional no que é permissível questionar, ou ainda colocar em suspenso, a instituição toda". 


\section{O Tropo da Diferença}

Nesse contexto, um dos tropos principais da aula de literatura estrangeira deveria ser o tropo da diferença - o que se articula na intersecção entre o texto literário, o autor e o leitor. Se, por um lado, as narrativas são singulares e são reconhecidas pelo seu autor, pelo seu título, pela estória que narram, elas pertencem a uma complexa rede de significações que mudam e se renovam com cada leitura, dentro e fora da comunidade onde foi escrita, o que revela a interpenetração entre as diferentes comunidades discursivas.

Esse processo implica uma familiarização com metáforas e práticas literárias que não necessariamente vão coincidir com aquelas da nossa cultura, porque respondem a uma concepção de literatura que tem a ver com outras comunidades interpretativas (FISH, 1982). Essas considerações revelam que o valor do literário ou a distinção entre o literário e o não literário não é fixo, nem está inscrito no texto, mas é cultural e depende da relação que se estabelece entre o leitor e o texto.

Por sua vez, as características formais do texto articulam diferenças culturais. A modo de exemplo, a estrutura da narrativa, linear, circular ou episódica, está diretamente relacionada com o conceito de tempo. Por exemplo, Hughes \& Trautman (1995, p. 172) apontam que nas comunidades judeu-cristãs o conceito de tempo é linear e implica nascimento, vida e morte. $\mathrm{Na}$ comunidade hindu, a reencarnação apresenta o conceito de tempo de maneira circular, uma passagem contínua entre uma vida e outra, o que vai implicar uma forma diferente de enredo que, mais do que se organizar em princípio, meio e fim, implica um constante recomeçar.

Ao mesmo tempo, a estrutura episódica das narrativas indianas faz com que a estória seja narrada por meio de uma série de enredos e subenredos que se complementam uns com outros, revelando a pluralidade e polifonia da comunidade indiana. Colocar o foco em um ou outro episódio faz com que a narrativa adquira uma significação diferente (PANIKER, 2003).

Assim, aspectos sociais e estéticos se complementam: a leitura dos textos literários não se reduz a aspectos culturais, nem a uma leitura puramente estética, mas são leituras em que o contexto cultural define a estética e, por sua vez, a estética ajuda a melhor formular temas culturais. 
No caso de uma literatura multicultural produzida em língua inglesa, em que o professor se defronta com várias tradições literárias na sua sala de aula, isso implica se familiarizar com diferentes epistemologias estéticas e sistemas culturais, para não reduzir os textos literários a narrativas sociais, ou desqualificar sistemas artísticos, simplesmente porque eles não coincidem com os nossos.

\section{Reflexões finais}

Entendemos que a estética da diferença é central em um mundo dividido pelos conflitos entre as diferentes comunidades da sociedade globalizada. Nesse contexto, ensinar a diferença, por meio do curriculum transcultural, torna-se central, porque as narrativas que o compõem narram as dificuldades enfrentadas pelas pessoas que moram nas nações pós-coloniais, assim como também a vida daqueles que emigraram para as nações do centro e sofrem discriminação.

Então, ensinar a diferença implica ensinar as condições não só literárias, mas culturais, sociais e políticas que informam a comunidade onde a narrativa foi escrita. Nesse sentido, o texto literário não é um fim em si mesmo, mas uma zona de contato que ajuda a desconstruir as visões, muitas vezes negativas, de outras comunidades que os alunos trazem para a sala de aula, especialmente quando essa diferença se apresenta como uma ameaça para a própria identidade. Por sua vez, essa atitude não fundamentalista da comunidade do Outro leva à autorreflexão sobre a própria comunidade. Nessa instância, a diferença adquire um novo valor: de processo de exclusão torna-se em processo de conhecimento e autoconhecimento. É, nesse processo, que a literatura se torna um âmbito de ação social.

Contudo, como assinala Helen Hoy (2001, p. 11), o conceito de diferença é assimétrico e implica a pergunta "Diferença, mas do ponto de vista de quem"? A escritora discute o caso de escritores nativos canadenses que sempre são questionados sobre o que significa ser um escritor nativo, ou sobre os costumes das suas comunidades, mas nunca sobre o seu processo de escrita. Ou seja, a sua diferença é restrita a questões de raça.

Então, se por um lado, ignorar a diferença tem um efeito negativo, por outro, fixar-se nela tornando-a o único tropo, no caso de comunidades consideradas como minorias ou margin- 
alizadas, tem um caráter redutivo e restritivo. Hoy ilustra esse aspecto citando a narrativa Traplines (1996), de Eden Robinson, na qual um homem branco, em uma quermesse beneficente, vai comer um pão feito por um nativo e pergunta, de propósito, para a moça que o está servindo: "E como devo comer este pão?" e ela responde "Com a boca, idiota". Fixar o outro na diferença pode se tornar ofensivo no sentido de que o faz tão diferente que lhe tira a humanidade.

Porém, como acrescenta Hoy (2001, p. 8), muitas vezes há um desejo, por parte dos membros de algumas comunidades, de enfatizar sua diferença e ser marcadamente Outro. Essa atitude se reflete na sua resistência a que outras pessoas (de fora da sua comunidade) se apropriem de suas narrativas, porque só eles as podem narrar e entender. Essa atitude transcendentaliza a diferença e a associa com um conceito de verdade, entendido como fixo e permanente, que implica que eles sempre são entendidos da mesma maneira por todos os membros da comunidade, o que se torna impossível para pessoas alheias. Por isso não admitem nem posicionamentos, nem interpretações diferentes.

Pela ótica oposta, uma advertência que deve ser feita, como aponta Hoy (2001, p. 9), é que o discurso do pós-colonialismo, no seu desejo de incluir todos pode se tornar em uma narrativa mestre e unívoca que não somente apaga, mas se torna uma autoridade incontestável sobre a diferença. Os críticos pós-coloniais, que pertencem, muitas vezes, ao Primeiro Mundo, continuam enxergando as narrativas do Terceiro Mundo de uma ótica que traduz a desigualdade ou em condescendência ou em superioridade teórica. Needham (1992, p, 38) explica esse processo dizendo que há desigualdades radicais na maneira como o Primeiro Mundo continua a se posicionar sobre o Terceiro Mundo não somente em aspectos materiais, mas discursivos, e o torna um objeto de interpretação. Um exemplo, aponta a autora, seria a recepção que teve no Primeiro Mundo a sentença de morte que Khomeini imputou a Salman Rushdie, devido à publicação de Os Versos Satânicos. Imediatamente, no Ocidente se interpretou Rushdie como um indivíduo que tinha direito de expressão, característico do Primeiro Mundo e ausente no Terceiro Mundo, onde reinam supremos o fanatismo e o autoritarismo. 
O título do livro de Hoy, Como deveria ler essas [estórias]? aponta para esses conflitos: a diferença entendida como irredutível que sempre coloca uns em um nível de superioridade comparados com o Outro, ou uma familiaridade presunçosa. Uma maneira de negociar a diferença seria, não somente por via do cânone multicultural, mas pela reformulação do conceito de narrativa e da leitura dos textos literários não como narrativas universais, ou transcendentais, mas como processos de significação que vão variar segundo o contexto cultural e as relações de poder que se estabelecem entre as pessoas envolvidas nesse processo.

\section{REFERÊNCIAS}

ARNOLD, Matthew. [1869] Culture and Anarchy. London: Oxford World Classics, 2006.

BHABHA, Homi. The Location of Culture. London: Routledge, 1994.

BRYDON, Diana. "Developing New Literacies in CrossCultural Contexts". MS, 2009.

CAPUTO, John D. Against Ethics. Bloomington and Indianapolis: Indiana University Press, 1993.

CHAMBERLIN, J. Edward Where are your Stories? Finding Common Ground. Canada: Alfred A. Knof, 2003.

DAMROSCH, David. How to Read World Literature. Malden, MA: Wiley-Blackwell, 2009.

DERRIDA, Jacques. Acts of Literature. New York \& London: Routledge, 1992.

. "Structure, Sign and Play in the Discourse of the Human Sciences". In Modern Criticism and Theory. D.Lodge, ed. London \&New York: Longman, 1988. (108-124).

DEWEY, John. [1934] Art as Experience. London: Perigee, 2005. EAGLETON, Terry. The Ideology of Aesthetics. Cambridge: Blackwell, 1990.

ELIOT, T. S. [1919] "Tradition and the Individual Talent" In Selected Essays.London: Faber \& Faber Limited, 1951.

ELLIOTT, Emory et al. Aesthetics in a Multicultural Age. Oxford University Press, 2002. 
FESTINO, CIELO. Uma Praja ainda imaginada. A representação da nação no romance indiano de língua inglesa. São Paulo: EDUSP/ Nankin, 2007.

FISH, Stanley. "Is There a Text in this Class?" In Is There a Text in this Class? The Authority of Interpretive Communities. Cambridge, Ma \& Harvard, England: Harvard University Press, 1982.

FREITAS CATON, Louis "Afterword" In Aesthetics in a Multicultural Age. Oxford University Press, 2002.

GIROUX, Henry. "Is There a Role for Critical Pedagogy in Language/Cultural Studies? An Interview with Henry A. Giroux. Manuela Guilherme In Language and Intercultural Communication. Vol 6:2, 2006. Clevedon, GB.

HALL, Stuart. "Political Belonging in a World of Multiple Identities" In Conceiving Cosmopolitansim. Steven Vertovec \& Robin Cohen, eds. Oxford U. Press, 2002.

HOY, Helen. How Should I Read These? Native Women Writers in Canada.University of Toronto Press, 2001.

HUGHES, Diane \& T.R. Trautmann. Time. Histories and Ethnologies. The University of Michigan Press, 1995.

ICKSTADT, Heinz "Toward a Pluralist Aesthetics" In Aesthetics in a Multicultural Age. Emory Elliott et al, eds. Oxford U. Press, 2002.

LAUTER Paul. "Aesthetics Again? The Pleasures and the Dangers" In Aesthetics in a Multicultural Age. Emory Elliott et al, eds. Oxford U. Press, 2002.

LIMBALE, Sharankumar. Towards an Aesthetic of Dalit Literature. Trad do Marathi de Alok Kumar Mukherjee. New Delhi: Orient Longman, 2004.

MACAULAY, Thomas Babington. "Minute in Indian Education" In Selected Writings. The University of Chicago Press, 1972.

NEEDHAM, Amuradha Dingwaney. "At the Receiving End: Reading 'Third' World Texts in 'First' World Context". In "Turning the Century": Feminist Theory in the 1990s. G. Carr, ed. London \& Toronto: Bucknewell U. Press, 1992.

PALMER, D. J. The Rise of English Studies. Oxford U. Press, 1965. PANIKER, K. Ayyappa. Indian Narratology. New Delhi: Indira Gandhi National Centre for the Arts, 2003. 
RAO, Raja. [1938]Kanthapura. New York: New Directions Paperbooks, 1967.

SAID, Edward. Orientalism. England: Penguin, 1978.

VISWANATHAN, Gauri. Masks of Conquest. Literary Study and British Rule in India.New York: Columbia U. Press, 1989.

\section{Abstract \\ The aesthetics of difference and the teaching of literatures in english}

The article aims at dicussing the concept of aesthetics and its relevance for the teaching of literatures in English at a time when the subject English Studies has been reformulated as Literatures in English in order to encompass literary narratives not only from canonical traditions such as the British or the American, but also from those countries that were once English colonies and today have their own national literary traditions in English. In this context, the concept of aesthetics will be considered in counterpoint with the concept of difference, both literary and cultural.

Keywords: aesthetics; difference; literary canon 